\title{
INFERTILITY RESOLUTION AS A FACTOR OF ADOPTION ADJUSTMENT
}

\author{
Yulia F. Lakhvich \\ Belarusian State University, Minsk, Republic of Belarus \\ E-mail: luf@tut.by
}

\begin{abstract}
The study examines the role of prospective adoptive parents' infertility resolution in their future adoption adjustment. Infertility resolution is considered to be a result of going through a series of emotional reactions: denial, anger and offence, guilt, despair and depression, acceptance (resolution). The author argues that adoption readiness implies the infertility resolution: adjustment and accepting of infertility emotions, as well as considering adoption as an alternative way to parenthood, which is not able to replace birth of one's own child. The problem was investigated in a short-term longitudinal study. In pre-adoption stage 65 prospective adoptive parents participated in semi-structured interviews that assessed their emotional reaction to infertility. In post-adoption stage (2 years later) adoptive families with different levels of adoption adjustment were analyzed depending on patterns of adoptive parents' emotional reaction to infertility before adoption. The results showed that infertility resolution of prospective adoptive parents is a significant factor of successful adoption adjustment.
\end{abstract}

Key words: adoption, adoption adjustment, adoptive parents, childlessness, infertility resolution.

\section{Introduction}

For the majority of people the ability to give birth to a child is perceived as something going with saying. Nevertheless, infertile marriage ${ }^{1}$ constitutes approximately $15 \%$ of all marriages on average (Дуда, 1996). There is, however, one more way of parenthood. It is connected with adoption.

As the experience shows mostly adoptive parents are the people from infertile marriages, who decided to adopt a child after long years of agonizing disappointment and stress related to their inability to have children and consumptive medical treatment. That is why it is quite logical that one needs to take into account the infertility experience of the family that decided to adopt a child as to understand the process of adoption and the conditions for its success. In particular, it is necessary to take into consideration the fact that after having decided to become parents of a child who is deprived of parental care, the adoptive parents also have "the burden" of deprivations in their life experience - deprivation of the opportunity to give birth to their own child and to become "fullfledged" biological parents.

1 Infertile marriage is a marriage where the desired pregnancy has not been achieved within the period of one year at condition of regular sexual relations without use of contraceptive means. 
A number of authors share the opinion that infertility is a serious life commotion and in most cases it is quite difficult to overcome it (Daly, 1988; Kraft, Polombo, Mitchel, Dean, Meyers \& Volume 1, 2012 Schmidt, 1980; Mahlstadt, 1985). It is connected with the fact that infertility blocks implementation of one of the main functions of a mature person - an ability to give birth to a child and to actualize oneself as a parent. Besides, an ability to have a child does not, as a rule, cause any doubts, and that's why when a couple finds out its inability to bear children, it causes the strongest shock.

As Mahlstedt notes (1985, p. 336-340) infertility experience does not only deprive a person of an opportunity to have natural kid but also presumes a number of other losses:

1. Loss (real or imaginative) of a significant relationship (often in the form of nonverbalized fear that spousal relations will not stand the infertility test).

2. Loss of health, an acceptable self or body image (treatment of infertility does harm health and damages a psychologically healthy attitude to one's body; besides, regulation of sexual contacts as to increase a possibility to get pregnant can damage the harmony of sexual relations making them mechanical).

3. Loss of status or prestige in the eyes of others (stigmatization of infertility and as a result there can occur various complications in establishing and maintaining relations with those families having children).

4. Loss of self-esteem or pride in oneself (as a result of inability to implement one of the main life functions: birth and upbringing of children).

5. Loss of security (occupational, financial, social, cultural), an adequate sense of competence or control.

By that Mahlstedt (1985) points out two directions of control loss. One the one hand, one loses control over oneself, one's body, emotions and even everyday activities. On the other hand, loss of control touches upon some key time parameters of human existence: the present and the future. A married couple subjects its life to the rhythm and periods of a doctor's consultations and some treatment procedures removing all other plans and activities to the background. Absolutely new feeling and emotions of envy, anger, bitterness about the pregnant, people with children can cause self-accusation and formation of one's own image as an image of a negative person. Spouses find out that they are not able to plan their life related a simple and natural process such as giving birth to children. As a result there occurs the feeling of helplessness and insecurity, and quite often it leads to a low self-esteem and loss of self-confidence.

Therefore, infertility becomes a life crisis, and people, who experience infertility, pass through a number of emotional reactions and stages, which are typical for any crisis experience: denial and isolation, anger, bargaining, depression and submission. All above-mentioned emotional responses were described in the classical model by E. Kuebler-Ross (Кюблер-Росc, 2001) as the stages of experiencing death or the stages of dying. Later this model was used as the basic one as to understand any crisis experience that includes certain deprivations and losses (Шефов, 2006). As related to the experience of infertility, the model by E. Kuebler-Ross was specified and as a result the following stages of emotional response to infertility crisis were determined: shock and denial, anger and insult, sadness, isolation, guilt, despair and depression, acceptance (resolution) (Spears, 1999, p. 6).

\section{Problem of Research}

In this article we focus not on the infertility crisis, but on its role in the adoption process. It is necessary to find answers to the following three questions: how psychological infertility adjustment is going on, what determines readiness of a childless couple to adopt a child and what role infertility experience plays in the process of further family adjustment to adoption.

It is necessary to point out that many researchers share the opinion that adoption problems, enduring feelings related to infertility or, in other words, "resolution" of the problem of infertility is considered to be an exclusively important criterion for evaluation if the family couple is ready to adopt a child and as to predict successful adoption (Castle, 1982; Daly, 1990; Kraft, Polombo, Mitchel, Dean, Meyers \& Schmidt, 1980; Menning, 1977; Spears, 1999).

By that, Daly (1990) points out that resolution of the infertility problem does not happen in- 
28 stantly and it is a complicated process of identity transformation that includes three main stages: 1) confidence in ability to give birth to a child and expectation of pregnancy; 2) realizing that biological parenthood is problematic; and 3) decision to adopt: refusal from a desire to have one's own child and identification of oneself with the role of an adoptive parent.

Castle (1982) expressed his opinion that "the ideal adoptive couples are those who are able to talk in some depth about the pain of finding that they are infertile but who seem now to have resolved this" (p. 10). It is also pointed out that when the issue of infertility has not been resolved with adoption, the couple starts to consider adoption as a second-rate variant in comparison with giving birth to their own child. Adoptive parents feel irritation when communicating with the child because he/ she is evidently different from them, and they feel difficulties when considering issues of his/ her origin, adoption and biological parents (Kraft, Polombo, Mitchel, Dean, Meyers \& Schmidt). As a result, as Menning (1977) states lack of processed feelings and emotions related to infertility can become the main reason of unsuccessful adoption.

Some surveys and researches point out some negative consequences of the infertility problem, which is psychologically unresolved by adoptive parents. So, Dukette (1984) specified that when parents did not reconcile themselves with their inability to give birth to a child, there are more difficulties in their interaction with the adopted child and the story of his/ her adoption. Also a higher level of emotional disorders among adopted children was identified, if their parents did not "survive" their grief related to the infertility problem (Sorosky, Baran \& Pannor, 1978). Besides in the research by Digiulio (1988) mental health of the adopted child depending on self-acceptance of his/ her adoptive parents was studied. It was determined that a high level of self-acceptance of adoptive parents ensures mental well-being of the child and a high level of his/ her acceptance by the adoptive parents. In this context recognition and acceptance of adoptive parents' feelings about their infertility is an important step towards acceptance of the adopted child.

Thus, before the infertile couple is psychologically ready to adoption, it should emotionally "resolve" its infertility problem. Its "resolution" assumes recognition and acceptance of the feelings toward their inability to have biological kids and awareness that adoption is an alternative way to parenthood, which can become replacement of giving birth to their own child (Castle, 1982; Daly, 1990; Kraft, Polombo, Mitchel, Dean, Meyers \& Schmidt).

In some cases, when the feelings and emotions related to infertility remain unprocessed adoption is started to be treated as a solution of the infertility problem. However, adoption solves the problem of childlessness but not of infertility problem. Infertility presupposes a loss of the number of unique phenomena related to biological parenthood: genetic succession, transfer to a child of the inherited capabilities (talents and gifts), pregnancy, delivery, feeding experiences, early experience of attachment and connection with a child, a possibility to become a parent (to grow and rear children). Adoption fills up only the last loss of infertility from all the above-mentioned ones - a possibility to grow and rear a child, and in some cases if an infant is adopted, it provides partially early experience of attachment and connection with a child (Spears, 1999). Therefore, an infertile couple that takes a decision on adoption should realize that to adopt a child is not the same as to have their own child, and it does not eliminate grief and duration of adaptation or adjustment period related to the infertility experience.

Thus, psychological adjustment to infertility presupposes that the family gradually goes from the stage of denial of the problem to its recognition and acceptance. The next step is reconsideration of the issue of parenthood significance in the life of the infertile couple. As a result, there are two variants for an infertile couple for their further marriage. Some families choose to have childless life, the life devoted to individual self-actualization, career, participation in public life. The others come to the decision that parenthood is really important for them and if they cannot achieve it in a natural way they need to search for alternative ways. In this case, it is adoption that can become an alternative way to be a parent.

\section{Research Focus}

The theoretical analysis of literature showed that a number of researches discuss the importance of mutual connection of the infertility problem and adoption. As a rule, it is about a complicated way 
to adoption related to the crisis experience of infertility (Daniluk, 2003; Sandelovsky, 1995; Shapiro, 1983), about specific peculiarities distinguishing experience of the infertile adoptive couples from the one of families able to give birth to a child (Brodzinsky, Huffman, 1988; Daly, 1988; Kalus, 2006; Kirk, 1984; Levy-Schiff, 1991). Despite the fact that many authors pointed out the importance of processing the infertility problem for adoptive parents (Castle, 1982; Daly, 1990; Kraft, 1980; Menning, 1977; Spears, 1999), actually the empirical researches in this field are ambiguous and scarce. Mostly the data obtained are connected with the discussion of the negative results of the infertility problem not resolved by the adoptive parents. By that, as a rule, the researches touched upon either the pre-adoption, or post-adoption periods, and at the same time there are no any comparative longitudinal studies in the field.

That is why the objective of this work was to empirically investigate which role is played by the factor of the emotional infertility problem resolution by adoptive parents in the following family adjustment to adoption. With this purpose, the adoptive families were studied both in the period of pre-adoption, and in the period of post-adoption.

\section{Methodology of Research}

\section{Sample of Research}

The research was carried out on the basis of the National Adoption Center of the Ministry of Education of the Republic of Belarus located in Minsk. Primarily, within the pre-adoption period, 73 prospective adoptive parents were interviewed - within one year they had been applying to the National Adoption Center and expressed their readiness to take part in the research.

On the whole, the sample of interviewees had the following social and demographic characteristics: 73 respondents ( 34 men and 39 women) aged from 23 to 56 had the average age of 36 . From them 13 people (18\% from the sample) were the respondents aged less than 30 (inclusively) and 60 people ( $82 \%$ from the sample) were the respondents aged older than 30 . The percentage ration of the educational level in the total was the following: $12 \%$ - general secondary education, $27 \%-$ secondary specialized education, and 53\% - uncompleted higher and completed higher education. Virtually all candidates to adopt a child are married -68 people ( $93 \%$ from the sample), with the remaining 5 people ( $7 \%$ ) who are single women. 23 respondents ( $32 \%$ from the sample) already have their children, and 50 people ( $68 \%$ from the sample) do not have children. It is also necessary to note that the overwhelming majority of the prospective adoptive parents (65 people (89\%)) to some extent faced the infertility problem or some complications with giving birth to their own child. Actually they were selected for the further short-term longitudinal study.

\section{Instrument and Procedures}

The study was carried out in two stages as a short-term longitudinal study. In the first pre-adoption stage 65 prospective adoptive parents participated in semi-structured interviews that assessed their emotional reaction to infertility. It was important to determine the stage of the emotional response to the infertility crisis of the prospective adoptive parents. The basis was the modified by Spears (1999) and related to the infertility experience version of E. Kuebler-Ross's classical model of experiencing death including the following stages: shock and denial, anger and insult, sadness, isolation, guilt, despair and depression, acceptance (resolution). Thus, the closer the stage of acceptance by a person, the higher the level of emotional "resolution" of the infertility problem is.

For the empirical study of the factor of emotional response of the prospective adoptive parents to the infertility problem semi-structured interview was designed. The determining question in the interview, on the basis of which we could come to conclusion about the stage of the relevant emotional response to the infertility crisis of the prospective adoptive parent, was the following closed question, "Choose the emotional response that is characteristic of you at the moment when you think of inability to have your own children". The respondents had to choose this or that emotional response at the scale from denial to acceptance of the problem as to answer this question. 
OF PSYCHOLOGY

IN THE $21^{\text {st }}$ CENTURY Volume 1, 2012

The second post-adoption stage was carried out two years later after the first pre-adoption stage. During this stage of the study the method of experts' questionnaires was used. A series of semistructured interviews was introduced with the inspectors of childhood safety from the educational departments (sections), who supervise the conditions of life and upbringing of a child in the adoptive family. It was found out how effective the adjustment process in the adoptive families had been going on. To determine the efficiency of the adjustment process to adoption 4 content blocks were determined in the structure of the interview as well as definite diagnostics parameters of efficiency within the framework of each of them: microenvironment of the family (trust, kindness, satisfaction with the relations), family upbringing characteristics (opinion of the parents about the child, attitude to the child, democratic upbringing component), child mental and physical development (mental and emotional state, physical state, correspondence of development to the age standards of mental and physical development, state of health) and social development of a child. The indicated parameters were evaluated by the researcher during the interview according to the naming dichotomy scale. As a result with the help of factor and cluster analysis methods 4 groups of adoptive families were identified, distinguishing themselves from each other by adoption adjustment efficiency. The most effective adoption adjustment group (group No. 2) was represented by 12 families. The less effective adoption adjustment group (No. 4) included 4 families of adoptive parents. Groups No. 1 (12 families) and No. 3 (8 families) took the middle position in adoption adjustment efficiency. Further these groups of families were compared according to the factor of emotional response of spouses to the infertility problem evaluated in the pre-adoption period. It was studied if there were any valid differences between the groups of families with a different degree of the infertility problem resolution in efficiency of their further adoption adjustment.

\section{Data Analysis}

The analysis of the obtained data was carried out with ${ }^{\varphi *}$-criterion - Fischer's angular transformation as well as with factor and cluster analysis.

\section{Results of Research}

In the pre-adoption period the study of emotional response of the prospective adoptive parents to the infertility problem showed the following results. $33.3 \%$ of the respondents accepted ("resolved") the infertility problem. It proves that they accepted emotionally the fact of their inability to have their own children and they were ready to definitive acceptance of an adopted child without trials to replace "the unachievable" own child with his/ her help. By that, almost a half of the respondents experienced sadness because of their awareness of inability to have a biological child ( $41.5 \%$ of the respondents). This reaction takes an interim position in the scale of experiencing feelings related to infertility. Therefore, it can be pointed out that almost half of all prospective adoptive parents is on a halfway to emotional acceptance ("resolution") of their infertility problem. At the same time the sadness reaction, which differs from such strong responses as depression, despair and grief, - is a calm version of emotional experience related to this or that problem. Also, it is possible that those people who feel sadness have already "overcome the crisis" and accepted the fact that they are unable to have their own children, and the sadness they feel is a light emotion after the experienced hard problem. Nevertheless, even in the last case the sadness response proves that the infertility problem has not yet been totally resolved by a prospective adoptive parent and at some moment is still "felt and experienced". The remaining adoptive parents feel guilt (3,9\% of the respondents), despair and depression (5.9\% of the respondents) which are related to their inability to have their own children or they deny any difficulties of the way to parenthood, though they objectively exist (11.8\% of the respondents).

In the post-adoption period on the basis of interview with the experts, the adoptive families by means of the factor and cluster analysis were divided into 4 groups distinguishing themselves by efficiency of adoption adjustment. Then the groups of families with different adoption adjustment efficiency were compared as to identify if there are valid differences in the degree of emotional resolution of the infertility problem by the spouses with the one in the pre-adoption period. In other 
words, there was a question about the role of the factor of emotional resolution of the infertility Volume 1, 2012 problem in the further efficiency of family's adoption adjustment.

The primary frequency analysis showed that over a half of women $(58.3 \%)$ and men $(54.5 \%)$, from group No. 2 (which is the most efficient group) in the stage of pre-adoption was characterized by the emotional acceptance of the infertility problem. In its turn over a half of women and from $40.0 \%$ to $66.6 \%$ of men from other less efficient groups in the pre-adoption period were at the stage of denial, sadness, guilt and depression. Further the coupled comparison of men and women from the four groups with different degree of efficiency of adoption according to the factor of emotional response to the infertility problem was carried out with the help of $\varphi_{-}$- criterion, Fischer's angular transformation.

The most adoption optimal version of the emotional response to the infertility problem, testifying to its psychological resolution, is acceptance. Therefore, the groups of families, different in their efficiency, were compared to point out how well-developed this emotional response was among the men and women from those groups in the pre-adoption period. The proofs of hypotheses were checked about the fact that the share of people (men and women) who resolved the infertility problem in the pre-adoption period, in group of families No. 2 (the most efficient families) is higher than in all other groups (No.No. 1, 3 and 4). These hypotheses were confirmed when comparing group No. 2 with groups No. 1 and 3 both for women (groups No.No. 2 and $1{ }^{\varphi} \underset{\text { emp; }}{=}=4.26 ; p<0.01$; groups No. No. 2 and $3_{\text {emp }}^{\varphi}=3.81 ; \mathrm{p}<0.01$ ), and for men (groups No.No. 2 and 1 j $\varphi_{\mathrm{mp}}=2.33 ; \mathrm{p}<0.01$; groups No.No. 2 and $3{ }_{\text {emp }}=3.27 ; \mathrm{p}<0.01$ ) who adopted a child. At the same time comparison of men and women from group No. 2 (the most efficient group) with the men and women from group No. 4 (the least efficient group) gave an unexpected result: there were no statistically valid differences detected. The further comparison between the remaining groups (No.No. 1 and 3, No.No. 1 and 4, No.No. 3 and 4) also did not allow to definitely put in order all four groups of families with different adoption efficiency in accordance with the factor of acceptance of the infertility problem in the period of pre-adoption. By that, the differences in acceptance of the infertility problem between the women from different in adoption efficiency groups was more explicit than between the men, as there was a greater number of valid differences between female adoptive parents from different family groups detected. This, in our opinion, testifies to the fact that taking into consideration the woman's position in the prospective adoptive families can be more significant as to predict further family efficiency.

Therefore it was pointed out that the majority of adoptive men and women from the most efficient family group in the pre-adoption period accepted the fact of their inability to have their own children. However, as to realize what characterized the family as a whole in the pre-adoption period and how these characteristics were connected with further adoption efficiency, it is necessary to take into account possible combinations of positions of a husband and a wife in the families according to the factor of the infertility problem resolution. It will allow to point out different types of prospective adoptive families and to identify which of them happened to be the most efficient after adoption.

The following types of prospective adoptive families were specified according to the factor of the infertility problem resolution:

- Families where both spouses accepted the infertility problem (or a single-parent family where a parent accepted the infertility problem).

- Families where a wife accepted the infertility problem and a husband did not.

- Families where a husband accepted the infertility problem and a wife did not.

- Families where both spouses did not accept the infertility problem (or a single-parent family where a parent did not accept the infertility problem).

As presented in Table 1, the group of the most efficient adoptive families (No. 2) is different from less efficient groups (No.No. 1, 3 and 4) and it is due to the fact that in a half of the families from this group both spouses in pre-adoption period psychologically resolved the infertility problem, and in the other groups there are no any families like that at all. Besides, all families where both a husband and a wife emotionally accepted the infertility problem, then became the most efficient adoptive families. At the same time in the less efficient groups (No.No. 1, 3 and 4) a half or even more families are characterized by the fact that both spouses did not resolve the infertility problem 
OF PSYCHOLOGY

IN THE $21^{\text {st }}$ CENTURY Volume 1, 2012

32

prior to adoption. These observations were statistically verified with the help of $\varphi_{\text {-criterion. The }}$ hypothesis was confirmed that the share of the families where both spouses in the pre-adoption period accepted their infertility problem is bigger in group of families No. 2 than in groups No. 1 $\left({ }^{\varphi}\right.$ emp $\left.=3.85 ; \mathrm{p}<0,01\right)$, No. $3\left({ }_{\text {emp }}=3.44 ; \mathrm{p}<0.01\right)$, No. $4\left({ }_{\text {emp }}=2.72 ; \mathrm{p}<0.01\right)$. Also the hypothesis was proved statistically valid that the share of the families where both spouses did not accept the infertility problem is bigger in groups No. $1\left(\varphi_{\text {emp }}=2.42 ; p<0.01\right)$, No. $3\left({ }^{\varphi}=2.72 ; p<0.01\right)$ and No. $4\left({ }_{\mathrm{emp}}=1.71 ; \mathrm{p}=0.044\right)$ than in group No. 2 .

Table 1. Acceptance of the infertility problem in families with different adoption efficiency (pre-adoption period) (in \%).

\begin{tabular}{|c|c|c|c|c|c|c|}
\hline \multicolumn{2}{|c|}{$\begin{array}{l}\text { Types of adoptive families according to the factor of } \\
\text { "acceptance" of the infertility problem }\end{array}$} & \multicolumn{5}{|c|}{ Groups of families with different adoption efficiency } \\
\hline & & $\begin{array}{c}1 \\
(n=12)\end{array}$ & $\begin{array}{c}2 \\
(n=12)\end{array}$ & $\begin{array}{c}3 \\
(n=8)\end{array}$ & $\begin{array}{c}4 \\
(n=4)\end{array}$ & Total \\
\hline \multirow{2}{*}{ No answer } & per cent in line & 42.9 & 14.3 & 42.9 & 0.0 & \multirow{2}{*}{19.4} \\
\hline & per cent in column & 25.0 & 8.3 & 37.5 & 0.0 & \\
\hline \multirow{2}{*}{$\begin{array}{l}\text { Both spouses accepted the infertility } \\
\text { problem }\end{array}$} & per cent in line & 0.0 & 100.0 & 0.0 & 0.0 & \multirow{2}{*}{16.7} \\
\hline & per cent in column & 0.0 & 50.0 & 0.0 & 0.0 & \\
\hline \multirow{2}{*}{$\begin{array}{l}\text { Wife accepted the infertility problem, } \\
\text { husband did not }\end{array}$} & per cent in line & 0.0 & 50.0 & 0.0 & 50.0 & \multirow{2}{*}{5.6} \\
\hline & per cent in column & 0.0 & 8.3 & 0.0 & 25.0 & \\
\hline \multirow{2}{*}{$\begin{array}{l}\text { Husband accepted the infertility } \\
\text { problem, wife did not }\end{array}$} & per cent in line & 33.3 & 33.3 & 0.0 & 33.3 & \multirow{2}{*}{8.3} \\
\hline & per cent in column & 8.3 & 8.3 & 0.0 & 25.0 & \\
\hline \multirow{2}{*}{$\begin{array}{l}\text { Both spouses did not accept the } \\
\text { infertility problem }\end{array}$} & per cent in line & 42.9 & 7.1 & 35.7 & 14.3 & \multirow{2}{*}{38.9} \\
\hline & per cent in column & 50.0 & 8.3 & 62.5 & 50.0 & \\
\hline \multirow{3}{*}{ No infertility problem } & per cent in line & 50.0 & 50.0 & 0.0 & 0.0 & \multirow{2}{*}{11.1} \\
\hline & per cent in column & 16.7 & 16.7 & 0.0 & 0.0 & \\
\hline & Total & 33.3 & 33.3 & 22.2 & 11.1 & 100.0 \\
\hline
\end{tabular}

Note: $n$-number of adoptive families with a definite adoption efficiency.

\section{Discussion}

In this study we put a question about the role of the factor of emotional resolution of the infertility problem in the following efficiency of family adjustment to adoption. As to specify it at the fist stage of the study in the-pre-adoption period we investigated at which stage of the emotional response to the infertility crisis the prospective adoptive families are. At the second stage of the study in the postadoption period (two years later after the first stage) by means of interviewing experts, we evaluated the fact how efficiently the adoptive families function. Further, the groups of families with different adoption adjustment efficiency were determined. These groups were compared between each other according to the degree of how the family could resolve the infertility problem prior to adoption.

Pair comparison of men and women from the four groups with different efficiency of adoption adjustment allowed to point out that the majority of adoptive parents from the most efficient group of families in the pre-adoption period accepted the fact of their inability to have their own children. Here one interesting fact is that a larger number of valid differences was detected between female adoptive parents from different family groups. In our opinion, it testifies to the priority significance of a woman's position in the prospective adoptive family as to predict further efficiency of their family.

This tendency can be explained in two ways, and each of them is connected with the specifics of the position and the role of a woman in the adoption process in comparison with the ones of a man. On the one hand, the essential circumstance reasoning the specific position of a female adoptive parent is the fact that a child adoption does not provide her with experience of pregnancy, expectation 
of a child, delivery and feeding, which are characteristic of the situation of biological parenthood. The prospective adoptive man in this case is less different from a future biological father, who, in Volume 1, 2012 comparison with a woman, in any case is far from prenatal and early postnatal experience. Thus, a woman when compared with a man, can be emotional over the fact that she is deprived of much more in the adoption process. Therefore, success of adoption can depend more on psychological readiness of the woman, on the extent to which she accepted the infertility problem. On the other hand, the significance of the psychological readiness of a woman to adoption for its further efficiency can be reasoned also by her more dominant position in the adoptive family. It is confirmed by the data of our study, which prove that in most cases the adoption initiator is a wife $(55.0 \%)$, and after adoption she spends, as a rule, more time with the adopted child than her husband does.

At the same time, comparison of men and women from different in their adoption efficiency groups according to the factor of acceptance of the infertility problem did not allow to definitely put the groups in order. As we see it, this result should not be interpreted as the one proving that there are no differences between these groups. It can prove that individual men and women from the groups with different efficiency of adoption differ from each other, but not to such a principal extent that this difference could definitely determine the following efficiency of the family as a whole. In this connection it is important to take into account the position of a husband and a wife, but it is not sufficient to evaluate the psychological readiness of the spouses to adoption and to predict further efficiency of their family.

This conclusion led us to the necessity to systematically use evaluation of adoptive families taking into consideration the positions of both a wife and a husband in their relation to the infertility problem. As a result, types of families with different combinations of the positions of wives and husbands in the families according to the factor of the infertility problem resolution were studied. This approach allowed us to determine what contributes in the position of a wife and a husband to a more efficient adjustment after adoption. It was found out that the most efficient group of adoptive families among all the rest groups distinguishes itself in the fact that there are validly more families in it where both spouses, prior to adoption, psychologically resolved the infertility problem. In other words, these families recognized and accepted their feelings about their inability to have their own children and they realized that adoption is an alternative way to parenthood, which cannot replace birth of their own child.

In its turn, in the groups of families with less efficiency there are validly more families where both spouses did not emotionally accept the idea that they would have no their own children. It is possible to presume that it could prevent them from accepting the adopted child without trials to compare it with their possible own child.

In this context it seems to be important to recollect the theory of social and role adoption adjustment developed by the Canadian scientist D. Kirk. Kirk (1984) gave grounds to the idea that adoption can be successful only when the adoptive parents realize the specifics of their parenthood, its principal difference from biological parenthood. Adoptive parents if compared with biological ones do not have initial integrity with a kid in the form of kinship. At the same time, adoptive parents can build up the relation with the kid in a different way, having realized that adoption is a "shared fate". Actually, adoption is based on integrity and interdependence of two fates - of the adoptive parents, and of the adopted child, and each of them had his/ her own deprivations, but they gave to both parties a possibility to find each other and to create a family. On the one hand, the adopted child was deprived of experience of any relations with the biological parents, actually, he/ she was deprived of his/ her roots, past. On the other hand, the adoptive parents were deprived of the possibility to have their own child, and they were deprived of the opportunity to continue their kinship, of their future. These deprivations determine interdependence of destinies of the adoptive parents and the adopted child, unite two fates in one. Judging from it, it is clear why those families, which prior to adoption emotionally accepted the infertility problem and can speak openly about it are also open to accepting the adopted child. They don't project an image of the unachievable biological child on him/ her, they do not try to substitute birth of a child with adoption. The obtained results are also in compliance with the idea expressed by Digiulio (1988) that acceptance by adoptive parents contributes to their acceptance of the adopted child.

Therefore, the study carried out by us allowed to empirically prove the ideas of a number of 
scientists and researchers (Castle, 1982; Daly, 1990; Kraft, 1980; Menning, 1977; Spears, 1999) that resolution of the infertility problem is a significant indicator of psychological readiness of a childless couple to adopt a child. Moreover, knowledge of how a family responses emotionally to the infertility problem prior to adoption allows to predict efficiency of the family adjustment after adoption. Here it is necessary to stress that when evaluating psychological readiness of a wife or a husband it is important not just to analyze individual readiness of a spouse, but to analyze psychological readiness of the couple. It is necessary to find out how the position of a husband and wife according to the factor of the infertility problem resolution matches. In particular, the most efficient are, as a rule, the families where both spouses psychologically resolved the infertility problem.

\section{Conclusion}

The empirical study, which was carried out, allowed to determine that resolution of the infertility problem in the pre-adoption period plays an essential role in the following efficient family adjustment to adoption. Adoptive families, which have become the most efficient ones, in the pre-adoption period distinguished themselves from other families by the fact that both spouses there "resolved" the infertility problem. In other words, the most efficient families were the ones where both spouses prior to adoption had formed a real and adequate idea of their parenthood. They "survived" their feelings on their way to accept infertility, and, therefore, they realized that parenthood of adoptive parents is absolutely different from biological parenthood and it cannot replace it, it is another, not the best one, but at the same time not the worst form of parenthood having both its complications and its unique perspectives. It is, as we see it, what makes this category of adoptive parents open to realizing adoption as the "shared destiny", and, as it follows, it makes it more successful in adoption.

We think that the results of this study are particularly important for those specialists who are involved directly in the process of selection and further accompanying of adoptive families. And it is necessary to point out the conclusion that only comprehensive evaluation of a family according to the factor of the infertility problem resolution is able to take into account the real psychological family resources for their further adoption adjustment.

\section{References}

Brodzinsky, D. M. \& Huffman, L. (1988). Transition to adoptive parenthood. Marriage and family review, $12(3-4), 267-286$

Castle, R. E. (1982). When adoption fails. Royal Society of Health Journal, 102 (1), 9-10.

Daly, K. (1988). Reshaped parenthood identity: The transition to adoptive parenthood. Journal of Contemporary Ethnography, 17 (1), 40-64.

Daly, K. (1990). Infertility resolution and adoption readiness. Families in Society: The Journal of Contemporary Human Services, 71 (October), 483-492.

Daniluk, J. C., \& Hurtig-Mitchell, J. (2003). Themes of hope and healing: infertile couples' experience of adoption. Journal of Counseling \& Development, 81 (Fall), 389-399.

Digilio, G. F. (1988). Self-acceptance: A factor in the adoption process. Child Welfare, 67 (5), 423-429.

Dukette, R. (1984). Values issues in present day adoption. Child Welfare, 63 (3), 233-243.

Kalus, A. (2006). Childlessness and adoption: The experience of loss as a source of suffering. Journal of Physiology and Pharmachology, 57 (4), 175-181.

Kirk, H. D. (1984). Shared fate: a theory and method of adoptive relationships. (Rev. Ed.). Port Angeles: Ben-Simon Publications.

Kraft, A. D., Palombo, J., Mitchell, D., Dean, C., Meyers, S., \& Schmidt, A. W. (1980). The psychological dimensions of infertility. American Journal of Orthopsychiatry, 50 (4), 618-628.

Levy-Schiff, R. (1991). Transition to parenthood in adoptive families. Developmental Psychology, 27 (1), $131-140$

Mahlstadt, P. P. (1985). The psychological component of infertility. Fertility and Sterility, 43 (3), $335-346$ 
Menning, B. E. (1977). Infertility: A guide for the childless couple. Englewood Cliffs, NJ: Prentice-Hall.

Sandelowski, M. A. (1995). Theory of the transition to parenthood of infertile couples. Research in Nursing and Health. 18 (2), 123-132.

Shapiro, C. H. (1982). The impact of infertility on the marital relationship. Social Casework, 63 (September), 387-393.

Sorosky, A. D., Baran, A., \& Pannor, R. (1978). The adoption triangle. New York: Anchor Press/ Dobleday.

Spears, D. A. (1999). Infertility and adoptive parenthood as predictors of marital adjustment: marital adjustment (Doctoral dissertation). Available from ProQuest Dissertations and Theses database. (UMI No. 9963723).

Дуда, І. У. (1996). Бясплоднасиьь. Г.П. Пашкоў (Рэд.), Беларуская энцыклапедыя у 18 тамах (Т. 3, С. 418). Мінск: Беларуская энцыклапедыя.

Кюблер-Росс, Э. (2001). О смерти и умирании. Киев: София.

Шефов, С. А. (2006). Психология горя. Санкт-Петербург: Речь.

Advised by Jan Lašek, University of Hradec Kralove, Czech Republic

Received: February 12, 2012

Accepted: March 15, 2012 